\title{
Glutamate dehydrogenase (GLUD1) expression in breast cancer
}

Madeleine L Craze, Rokaya El-Ansaria, Mohammed A. Aleskandaranya, Kiu Wai Chenga, Lutfi Alfarsia, Brendah Masisia, Maria Diez-Rodriguez ${ }^{a}$, Christopher C. Nolanª, R. Ian O. Ellisa,b, Emad A. Rakha $^{\mathrm{a}, \mathrm{b}}$ and Andrew R. Green ${ }^{\mathrm{a}}$

aNottingham Breast Cancer Research Centre, Division of Cancer and Stem Cells, School of Medicine, University of Nottingham, Nottingham City Hospital, Hucknall Road, Nottingham NG5 1PB

bCellular Pathology, Nottingham University Hospitals NHS Trust, Hucknall Road, Nottingham, NG5 $1 \mathrm{~PB}$

Correspondence:

Dr Andrew R. Green. Nottingham Breast Cancer Research Centre, Division of Cancer and Stem Cells, School of Medicine, University of Nottingham, Nottingham City Hospital, Hucknall Road, Nottingham NG5 1PB

Tel: (44) 115 8231407, Email: andrew.green@nottingham.ac.uk

\section{Running title: GLUD1 in breast cancer}

Key words: GLUD1, breast cancer, prognosis, triple negative, glutamine, metabolism 


\begin{abstract}
Dysregulated cellular metabolism is regarded as one of the hallmarks of cancer with some tumours utilising the glutamine metabolism pathway for their sustained proliferation and survival. Glutamate dehydrogenase (GLUD1) is a key enzyme in glutaminolysis converting glutamate to $\alpha$-Ketoglutarate for entry into the TCA cycle.

Breast cancer $(\mathrm{BC})$ comprises a heterogeneous group of tumours in terms of molecular biology and clinical behaviour, and we have previously shown that altered glutamine metabolism varies substantially among the different molecular subtypes.

We hypothesise that the prognostic value of GLUD1 expression will differ between the BC molecular subtypes and may act as a potential therapeutic target for BC tumours.

Methods: GLUD1 was assessed at the DNA, mRNA $(n=1,980)$ and protein $(n=1,300)$ levels in large and well-characterised cohorts and correlated with clinicopathological parameters, molecular subtypes, patient outcome and treatments.
\end{abstract}

Results: There was a correlation between GLUD1 mRNA and GLUD1 protein expression which were highly expressed in low grade Luminal/ER+ BC $(\mathrm{p}<0.01)$. GLUD1 mRNA and protein was associated with good patient outcome but not in any specific molecular subtypes. However, high GLUD1 protein expression was associated with a better outcome in triple negative (TN) patients treated with chemotherapy $(\mathrm{p}=0.03)$.

High GLUD1 mRNA was associated with the glutamine transporter, SLC1A5, and leucine transporter, SLC7A8 as well as mTOR $(\mathrm{p}<0.0001)$.

Conclusion: We provide comprehensive data indicating GLUD1 plays an important role in Luminal/ ER+ BC. GLUD1 expression predicts a better patient outcome and we show that it has the potential for predicting response to chemotherapy in TNBC patients. 


\section{INTRODUCTION}

Dysregulated tumour metabolism is an important step in oncogenesis and is acknowledged as one of the revised hallmarks of cancer, whereby cancer cells are able to modify and re-programme their metabolism to most effectively provide the energy required for proliferation and survival [1].

One of the most well described metabolic changes in tumour cells is the Warburg effect where glycolysis is utilised to support the increased energy requirement for the rapid growth of tumour cells, even in the presence of oxygen [2]. Besides glycolysis, glutaminolysis is also proving to be an essential metabolic pathway where the amino acid glutamine (Gln) is used to sustain proliferation and survival [3]. Indeed, many tumour cells undergo metabolic re-programming which makes them highly dependable upon this amino acid, and glutamine deprivation results in growth arrest and cell death [4].

There is abundant evidence surrounding the regulation of dysregulated tumour metabolism by oncogenes and/or tumour-suppressor genes such as c-Myc and p53, which are able to modulate the expression and activity of key transporters and enzymes involved in glutaminolysis [5-7].

$\mathrm{BC}$ heterogeneity is well documented and dysregulated metabolism during tumourigenesis can vary substantially among the different molecular subtypes of BC. Differences in metabolic profiles have been shown to discriminate between oestrogen receptor positive (ER+) and triple negative breast cancers (TNBC) [8], whereby TNBCs have an increased expression of metabolic enzymes involved in glutaminolysis and ER+ BCs which have the lowest level of these enzymes $[9,10]$.

HER2 positive tumours have the highest levels of Gln metabolism with increased expression of Glut aminase (GLS) and glutamate dehydrogenase (GLUD) [10]. This is in concordance with higher levels of glutamate and lower levels of Gln in TNBC and HER2+ tumours compared with ER+ tumours suggesting an increase in Gln consumption and glutaminolysis in these tumours [8, 11].

Oncometabolism is rapidly becoming an attractive field for therapeutic intervention and the differences observed in metabolic signatures between ER- and ER+ tumours may further guide therapy and predict disease outcome as well as allowing for the emergence of novel targets for therapeutic approaches to improve efficacy and reduce resistance.

We have previously reported the importance of the glutamine-proline regulatory axis in the highly proliferative luminal subgroup of BC and its regulation by MYC [12]. GLUD is a key enzyme in glutaminolysis converting glutamate to $\alpha$-Ketoglutarate $(\alpha-K G)$ for entry into the TCA cycle, reducing $\mathrm{NAD}(\mathrm{P})+$ to $\mathrm{NAD}(\mathrm{P}) \mathrm{H}$ in the process. GLUD is activated by the direct binding of the essential amino acid leucine which stimulates the deamination of glutamate and hence the production of $\alpha-\mathrm{KG}$. In humans two different isoenzymes of GLUD exist, GLUD1 and GLUD2, both of which are upregulated in human cancers enabling the cancer cell to utilise this pathway for growth and proliferation [13]. Studies have shown that in the cancer cell GLUD1 is not only essential for sustaining the TCA cycle for rapid proliferation and growth, but also has a role in the activation of mTORC1 [14] and as a regu- 
lator of redox homeostasis, whereby the inhibition of GLUD1 results in imbalanced redox homeostasis and a reduction in cancer cell proliferation and growth [15].

In this study, we aimed to determine the role of GLUD1 in BC by assessing gene copy number, mRNA and protein expression in large well characterised annotated cohorts of $\mathrm{BC}$ to determine its biological and clinical relevance within the different molecular subtypes, hypothesising a potential role within the higher proliferating, more aggressive forms of $\mathrm{BC}$. 


\section{MATERIALS AND METHODS}

\section{GLUD1 gene expression}

GLUD1 gene expression was evaluated in a cohort of 1,980 breast cancer samples using the Molecular Taxonomy of Breast Cancer International Consortium (METABRIC) cohort [16]. The METABRIC study provides data on genomic and transcriptomic profiling of breast cancer using the Affymetrix SNP 6.0 and Illumina HT-12 v3 platforms respectively. In addition, TP53 mutational profiling was performed. Detailed description of the experimental assays and analytical methods used were described previously [17]. In this cohort, patients with ER+ and/or lymph node negative tumours did not receive adjuvant chemotherapy, whilst those with ER- and/or lymph node positive tumours received adjuvant chemotherapy. Dichotomisation of GLUD1 mRNA expression was performed using X-tile (Version 3.6.1, Yale University, USA) based on prediction of breast cancer specific survival (BCSS) [18]. The BCSS is defined as the time (in months) from the date of primary surgery to the date of BCrelated death. The relationship between gene copy number aberrations, both gains and losses, of GLUD1 and MYC and p53 mutations with GLUD1 mRNA expression and patient outcome were also investigated.

To validate the data on the GLUD1 mRNA expression, bc-GenExMiner v4.0 (Breast Cancer GeneExpression Miner v4.0) online dataset (http://bcgenex.centregauducheau.fr) was used as an external validation dataset [19].

\section{GLUD1 protein expression}

Immunohistochemistry was conducted using a large cohort of patients comprising a well-characterised consecutive series of early stage (TNM Stage I-III excluding T3 and T4 tumours) sporadic primary operable invasive BC. Patients (age $\leq 70$ years) were enrolled into the Nottingham Tenovus Primary Breast Carcinoma Series, presented at Nottingham City Hospital between 1989 and 1998 $(\mathrm{n}=1,300)$ and managed in accordance to a uniform protocol. Patients' clinical history, tumour characteristics, information on therapy and outcomes are prospectively maintained. Outcome data was collected on a prospective basis and included development and time to distant metastasis (DM) and BCSS. DM free survival (DMFS) is defined as the time (in months) from the date of primary surgery to the appearance of DM.

The clinicopathological parameters for Nottingham and METABRIC series of patients are summarised in Supplementary Table 1.

\section{GLUD1 Antibody Validation}

GLUD1 primary antibody specificity (Rabbit monoclonal, Ab168352, Abcam Plc, Cambridge UK) was determined using western blotting with MCF7 and MDA-MB-231 human BC cell lines (obtained from the American Type Culture Collection; Rockville, MD, USA). GLUD1 primary antibody was used at a 1:250 dilution and IRDye 800CW Donkey anti-Rabbit fluorescent secondary antibody (92632213, LI-COR Biosciences) was used at a 1:15000 dilution. Mouse monoclonal anti- $\beta$-actin primary 
antibody (1:5000, A5441, Sigma-Aldrich) with IRDye 680RD Donkey anti-Mouse fluorescent secondary antibody $(1 ; 15000,926-68072$, LI-COR Biosciences) was used as a control. Samples were loaded at $10 \mu \mathrm{g}$ alongside the protein ladder (26619, PageRuler Plus Prestained Protein Ladder, Thermo Scientific) to determine the correct molecular weight. Odyssey Fc with Image Studio 4.0 was used to visualise protein bands (LI-COR Biosciences) which showed a single specific band at the predicted molecular weight of $62 \mathrm{KDa}$ (Figure 1A).

\section{Tissue arrays and Immunohistochemistry}

Tissue microarrays (TMAs) were constructed as previously described [20]. Immunohistochemical staining for GLUD1 was performed on $4 \mu \mathrm{m}$ thick sections using the Novolink polymer detection system (Leica Biosystems, RE7150-K), as per manufacturer's instructions. Heat mediated antigen retrieval was carried out using citrate buffer pH 6.0. GLUD1 primary antibody was used at a 1:100 dilution for 30 minutes at room temperature. Negative (omission of the primary antibody) and positive controls were included according to manufacturer's data sheet.

\section{Assessment of GLUD1 Protein Expression}

Stained TMA sections were assessed using high resolution digital images (NanoZoomer; Hamamatsu Photonics, Welwyn Garden City, UK) at x20 magnification. Assessment of staining for GLUD1 was based on a semi-quantitative assessment of immunoreactivity using a modified histochemical score (H-score) which includes an assessment of both the intensity of staining and the percentage of stained cells [21]. For the intensity, a score index of $0,1,2$ and 3 corresponding to negative, weak, moderate and strong staining was used and the percentage for each was estimated subjectively. A final score of 0 to 300 is the product of both the intensity and the percentage.

Scoring was carried out by KC and for inter-observer concordance, $10 \%$ of the cores were second scored by a pathologist (MA) blinded to previous scores, clinicopatholigcal variables and survival data.

Dichotomisation of GLUD1 protein expression was determined based on breast cancer specific survival (BCSS) using X-tile software [18].

Immunohistochemical staining and dichotomisation of the other biomarkers included in this study were as per previous publications [5]. ER and PgR positivity was defined as $\geq 1 \%$ staining. Immunoreactivity of HER2 was determined using standard HercepTest guidelines (Dako). Chromogenic in situ Hybridisation (CISH) was used to quantify HER2 gene amplification in borderline cases using the HER2 FISH pharmDx ${ }^{\mathrm{TM}}$ plus HER2 CISH pharmDx ${ }^{\mathrm{TM}}$ kit (Dako) and was assessed according to the American Society of Clinical Oncology guidelines. BC molecular subtypes were defined based on the immunohistochemical profile as: Luminal A: ER+/HER2- Low Proliferation (Ki67<10\%). Luminal B: ER+/HER2- High Proliferation (Ki67 $\geq 10 \%$ ). HER2-positive class: HER2+ regardless of ER 
status. Triple Negative (TN): ER-, PgR- and HER2-. Basal phenotype was defined as those tumours expressing cytokeratin (Ck) 5/6, and/or Ck14 and/or Ck17.

\section{Statistical analysis}

Statistical analysis was performed using SPSS 21.0 statistical software (SPSS Inc., Chicago, IL, USA). Univariate and multivariate analyses were performed by chi-squared test, Log rank and Cox regression analysis, respectively. One way ANOVA (Tukey) and Spearman's Correlation coefficient were used for continuous data. Survival curves were analysed by the method of Kaplan-Meier (Kaplan and Meier, 1958). A p-value $<0.05$ was considered significant. This study complied with reporting recommendations for tumour marker prognostic studies (REMARK) criteria [22].

\section{Ethics}

This study was approved by the Nottingham Research Ethics Committee 2 under the title 'Development of a molecular genetic classification of breast cancer'. 


\section{RESULTS}

\section{GLUD1 in breast cancer}

A total of 26/1,980 (1.3\%) of cases showed a copy number gain of GLUD1 and 58/1,980 (2.9\%) showed a copy number loss. The distribution of GLUD1 mRNA expression in the METABRIC cohort showed high expression ( $\log 2$ intensity $>10.0$ units in 909/1,980 (46\%)). Loss of GLUD1 was correlated with lower GLUD1 mRNA expression and gain of GLUD1 was associated with higher GLUD1 mRNA expression (both $\mathrm{p}<0.001$, Figure $2 \mathrm{~A}$ ).

GLUD1 protein expression was observed in the cytoplasm of breast tumour cells ranging from absent to high (Figure 1B-1D), with high protein expression (>215 H-score) being observed in 367/1,300 $(28 \%)$ of tumours. There was a significant correlation between GLUD1 mRNA expression and GLUD1 protein expression (correlation coefficient $=0.161, \mathrm{p}=0.021$ ).

\section{GLUD1 is associated with clinicopathological parameters of good prognosis}

Higher GLUD1 mRNA expression was significantly associated with lower tumour grade (Figure 3A, Table 2, $\mathrm{p}<0.001$ ) and lymph node stage (Figure 3B, Table 2, $\mathrm{p}<0.001$ ). The association between GLUD1 mRNA and tumour grade, but not nodal stage, was confirmed using the Breast Cancer GeneExpression Miner v4.0 (Supplementary Figure 1A). There was also a significant association between high GLUD1 mRNA and lobular and special type tumours ( $\mathrm{p}<0.001$, Figure $3 \mathrm{~J}$ and Table 2$)$. A similar association was observed between high GLUD1 protein expression and lower tumour grade $(p=0.047$, Table 2).

High expression of GLUD1 mRNA and GLUD1 protein were significantly associated with ER+, and $\mathrm{PgR}+$ tumours (all $\mathrm{p}<0.001$; Table 2 and Figure 3C-D). Additionally, high GLUD1 mRNA, but not GLUD1 protein, expression was significantly expressed in HER2 negative tumours $(p<0.001$; Table 2 and Figure 3E). High GLUD1 mRNA and GLUD1 protein was associated with non-TN tumours $(\mathrm{p}<0.001$; Table 2 and Figure 3F).

In addition, loss of GLUD1 copy number was associated with high grade tumours $(p=0.001)$, ER$(p=0.008)$, HER2- $(p=0.012)$ and TN $(p<0.001)$ tumours (Table 1$)$.

\section{GLUD1 is differentially expressed within the molecular subtypes of BC}

When comparing the levels of GLUD1 mRNA expression in the intrinsic (PAM50) molecular subtypes, high expression was observed in Luminal A and B classes (Figure $3 G, p<0.001$ ). Association of GLUD1 mRNA with these classes was confirmed using the Breast Cancer Gene-Expression Miner v4.0 (Supplementary Figure 1F). Similarly within the METABRIC Integrative Clusters, high GLUD1 mRNA expression was associated with clusters 2 (Luminal A and Luminal B tumours) and 7 (Luminal A tumours) (Figure $3 \mathrm{H}, \mathrm{p}<0.001$ ), and low levels of GLUD1 mRNA expression was observed in cluster 10 (TN tumours). In the SCMGENE subtypes there was a higher expression of GLUD1 mRNA in ER+/HER2- tumours compared with HER2+ and ER-/HER2- tumours ( $<<0.001$; Figure 3I). ER+/ 
HER2- Low Proliferation tumours had a significantly higher expression of GLUD1 mRNA than ER+/ HER2- High Proliferation tumours $(\mathrm{p}=0.02)$.

Similarly, expression of GLUD1 protein in BC subtypes showed a significantly higher expression in ER+/HER2- tumours compared with the other subtypes ( $<<0.001$, Table 2).

Both Luminal B and Basal subtypes showed a greater copy number loss of GLUD1 ( $\mathrm{p}<0.001)$ with a similar trend for GLUD1 copy number gain (Table 1).

\section{GLUD1 showed significant molecular association with other significant biomarkers}

We investigated correlation of GLUD1 mRNA expression with associated glutaminolytic genes using the METABRIC dataset which are summarised in Table 4. The genes were selected based on previous publications, being either regulatory genes or others that share or support the biological function of GLUD1. There was a positive correlation between GLUD1 with several amino acid transporters including SLC7A5 $(\mathrm{p}<0.001)$ and genes involved in the glutamine-proline regulatory axis including $A L D H 18 A 1$ ( $\mathrm{p}<0.001)$. There was an inverse relationship between GLUD1 and MYC, and the MYC regulated gene NDRG2. At the protein level, high GLUD1 was associated with low c-MYC expression $(\mathrm{p}<0.001)$, ALDH18A1 ( $=0.007)$ and SLC7A5 ( $\mathrm{p}=0.025)$ (Table 5) but not any other amino acid transporters or enzymes involved in glutaminolysis.

High GLUD1 protein expression was significantly expressed in breast tumours that were negative for, PI3K $(p<0.001)$ and the cell cycle regulator Cyclin E ( $p=0.006$, Table 3$)$. High expression of GLUD1 was positively associated with high levels of Bcl-2 ( $\mathrm{p}=0.022)$ and pAKTs437 $(\mathrm{p}<0.001$; Table 3$)$. There was no association between GLUD1 and Ki67.

When investigating the subtypes of BC, the negative relationship between $M Y C$ and GLUD1 was only observed in Luminal A ( $\mathrm{p}=0.001)$ and Luminal B $(\mathrm{p}=0.015)$ subtypes. In ER+ tumours, high GLUD1 mRNA expression was specifically associated with those enzymes involved with the Pro-Gln regulatory axis. The majority of amino acid transporters were significantly associated with GLUD1 expression in ER+ tumours and to a lesser extent TN and Basal tumours. SLC1A5, SLC38A1, SLC7A5, and $S L C 7 A 8$ were significantly expressed with GLUD1 in all subtypes. Correlations between GLUD1 expression and $m T O R$ were observed in the Luminal A and Basal molecular subtypes, along with $V E G$ $F A$, whereas $V E G F B$ was only seen in ER+/HER2- tumours (Table 4). A similar pattern of co-expression of GLUD1 and other genes was observed using the Breast Cancer Gene-Expression Miner (Supplementary Table 2) particularly in ER+ tumours with genes involved in the Pro-Gln regulatory axis.

\section{GLUD1 expression is associated with patient outcome and response to chemotherapy}

High GLUD1 mRNA $(\mathrm{p}<0.001)$ and GLUD1 protein $(\mathrm{p}=0.006)$ expression were both associated with a good BCSS (Figure 4A and 4B). However, when investigating associations with outcome within the molecular subtypes, high expression of GLUD1 was only predictive of longer BCSS in Luminal A tumours at the mRNA level ( $\mathrm{p}=0.027$, data not shown). There was no association between GLUD1 mRNA or protein and outcome in the other molecular subtypes. 
The relationship between high GLUD1 mRNA expression and good patient outcome in ER+ disease, but not ER- disease, was confirmed using Breast Cancer Gene-Expression Miner (Supplementary Figure 2). $\mathrm{CN}$ loss or gain of GLUD1 was associated with poor patient survival $(\mathrm{p}=0.002 ; \mathrm{p}=0.044)$ (Figure 2B and 2C).

In multivariate Cox regression analysis, GLUD1 protein, but not GLUD1 mRNA, was an independent predictor of BCSS in all cases ( $\mathrm{p}=0.005)$ (Table 6).

When considering TNBC patients treated with chemotherapy, patients with high GLUD1 protein expression had a significantly better outcome (Figure $5 \mathrm{C}, \mathrm{p}=0.027$ ) whilst those patients who did not receive chemotherapy had no survival advantage (Figure $5 \mathrm{~B}, \mathrm{p}=0.570$ ). 


\section{DISCUSSION}

Metabolic reprogramming in cancer including BC provides a vital role in the provision of supplementary elements including nutrients and energy which are essential for cellular growth. Some tumour cells are reliant on glutamine metabolism and become "addicted" to this amino acid for sustained proliferation/survival.

Studies that address the prognostic significance of the enzyme GLUD1 in BC and its potential influence on Gln metabolism remains limited.

We therefore investigated GLUD1 at the genomic, transcriptomic and proteomic level utilising a large number of breast tumours in order to better understand the potential role of this enzyme in BC and its molecular subtypes.

In this study, we have shown for the first time that high GLUD1 expression at the mRNA and protein level is associated with tumours of good prognosis; specifically tumours of lower grade and hormone receptor positivity $(\mathrm{ER}+/ \mathrm{PR}+)$.

Kim et al., 2013, investigated the expression of glutamine metabolism-related proteins in a smaller study, including GLUD1, within the different molecular subtypes of breast cancer showing that high expression of tumoural GLUD1 protein was observed in the HER2+ and Luminal A/B subtypes compared with TNBC [10]. In our study, we confirm the relationship with GLUD1 and luminal tumours but we found no correlation between GLUD1 expression and HER2+ tumours.

We did observe a CN loss of GLUD1 which was significantly associated with ER-, HER2- and TN tumours as well as a greater $\mathrm{CN}$ loss being observed in Basal-like tumours.

Several studies have been carried out looking at quantitative proteomics to generate profiles in order to identify functional differences between the BC molecular subtypes [23, 24]. From these studies noticeable differences in energy metabolism networks between the subtypes of $\mathrm{BC}$ were revealed, suggesting the use and synthesis of metabolites to support growth and survival differs within each of the subtypes. For example, a significant increase in energy metabolism was observed in ER/PgR 'Luminal-like' tumours compared to a down regulation of this pathway in HER2+ tumours. KEGG and STRING analysis show higher expression of GLUD1 and glutamate-ammonia ligase/glutamine synthetase (GLUL) with lower expression of GLS within the ER+/PR+ tumours compared to the HER2+ and TNBC, however within the HER2 subtype upregulation of PYCR1 and PRODH, involved in proline metabolism, were observed [24].

$\mathrm{ER}+/ \mathrm{PR}+$ tumours were also predicted to have higher oxidative metabolism while the other subtypes have higher dependence on glucose and glutamine, with entire metabolic networks being associated with reduced glycolysis and increased oxidative phosphorylation in ER+/PR+ tumours [24]. 
Another study using computational modelling and metabolic phenotypic analysis (MPA), showed considerable metabolic differences between ER+ and ER- tumours, with 73\% of metabolic processes having significantly different MPA scores. This study identified an increase in glutamine uptake to be typical of ER- tumours and an increase in glutamine production and secretion to be typical of ER+ tumours showing glutamine biosynthesis and secretion is significantly higher in ER+ whereas serine metabolism and glutamine uptake were significantly higher in ER- tumours [23]. These observation support the outcome of our study where we have shown the metabolic biosynthesis involving GLUD1 to be associated with the Luminal subtypes of BC.

The association of GLUD1 at the mRNA and protein level with key amino acid transporters and enzymes involved in glutaminolysis is not unsurprising. GLUD1 is the key enzyme in the second deamination step of glutaminolysis, where it is activated by the amino acid leucine to deaminate glutamate to $\alpha-K G$ for incorporation into the TCA cycle, which is a crucial anaplerotic step in proliferating cells. Leucine is known to activate mammalian target of rapamycin complex 1 (mTORC1) which has many functions in the cancer cell including; regulation of protein translation, prevention of apoptosis and cancer cell proliferation [25].

Several studies have shown the importance of glutaminolysis in the mTOR signalling pathway which, when active, mTORC1 is known to have a major role in promoting cancer cell growth and proliferation. mTORC1, one of the two multi-protein complexes, is regulated by several upstream signals including growth factors and nutrients such as amino acids and glucose. The amino acid leucine is thought to be a key activator of mTORC1 by stimulating the GTP state of the RagA/B complex which in turn recruits mTORC1 to the lysosome where it is activated by the lysosome-associated Rheb [26, 27].

Glutamine has also been implicated as an important amino acid for mTORC1 signalling as it can indirectly stimulate this pathway by increasing the uptake of leucine [28]. Recent findings also suggest leucine stimulates mTORC1 indirectly through glutaminolysis. Duran et al., 2012, demonstrated that glutamine, in combination with leucine, increased the GTP charge of exongenously expressed RagB, promoting mTORC1 activation and enhancing glutaminolysis and $\alpha-\mathrm{KG}$ production, suggesting glutaminoloysis and $\alpha-K G$ production may be key events for leucine to activate Rag-mTORC1 signalling [14]. As it is known that leucine directly binds and regulates GLUD1, enhancing the conversion of glutamate into $\alpha-\mathrm{KG}$, it was proposed that mTORC1 senses the fluctuations of glutamine and leucine together by sensing leucine-dependent production of $\alpha-K G$. However, as leucine isn't the only activator of GLUD1, several mechanisms could be at play [29].

Several of the amino acid transporter molecules are involved in transporting leucine into the cell in exchange for glutamine, including SLC7A5 and SLC7A8. 
In this study we observed high GLUD1 expression at the mRNA and the protein level to have an inverse correlation with the solute carrier SLC7A5 and a positive correlation with SLC7A8 at the mRNA level. SLC7A5 is highly associated with TNBC and SLC7A8 with ER+ tumours, suggesting within Luminal/ER+ tumours, SLC7A8 has a higher affinity for leucine transport which activates GLUD1 for its energy metabolism.

We also know that the Akt signalling pathway can activate mTORC1 via the TSC complex and that mTORC2 can activate Akt by the phosphorylation of Ser487. We have also showed at the protein level that high GLUD1 is associated with pAKTs487, suggesting the importance of this pathway within Luminal BC for proliferation and survival.

In this study, we have shown that GLUD1 is highly expressed in ER+ Luminal tumours and are related with good overall patient outcome. We have also shown high GLUD1 is associated with the transporters of glutamine and leucine and mTOR, suggesting this is the metabolic pathway utilised by these tumours for cell survival and proliferation.

In addition, we observed good patient outcome within TNBC patients who had high GLUD1 protein expression and received chemotherapy, compared with patients who did not receive chemotherapy. Further validation studies are required to confirm whether GLUD1 is able to predict response to chemotherapy within the poor prognostic TN patients. 
Table 1: Copy Number Aberrations (CNA) of GLUD1 in breast cancer and their associations with MYC CNA and BC molecular subtypes

\section{GLUD1 copy number}

No

Loss

Gain

$\chi^{2}$

(p-value)

\section{Grade}

1

2

3

Lymph Node

Stage

1

2

3

\section{Estrogen}

Receptor

Negative

Positive

Progesterone

Receptor

Negative

Positive

892 (94.9)

34 (3.6)

$24(2.3)$

$14(1.5)$

$3.5(0.178)$

1004 (96.5)

HER2

Negative

1656 (95.6)

$57(3.3)$

$20(1.2)$

$8.9(\mathbf{0 . 0 1 2})$

Positive

$240(97.2)$

$1(0.4)$

$6(2.4)$

Triple Negative

No

Yes

1063 (96.6)

$37(2.2)$

21 (6.6)

$20(1.2)$

$18.8(\mathbf{0 . 0 0 0 0 8})$

293 (91.6)

PAM50 subtype

Luminal A

703 (97.9)

$10(1.4)$

$5(0.7)$

$42.1(\mathbf{0 . 0 0 0 0 0 1})$

Luminal B

458 (93.9)

$20(4.1)$

$10(2.0)$

Basal

301 (91.5)

23 (7.0)

5 (1.5)

HER2

$3.3(0.507)$

$9.7(\mathbf{0 . 0 0 8})$

6 (1.9) 
Normal

197 (99.0)

$2(1.0)$

0

SCMGENE

ER+/HER2- Low

proliferation

ER+/HER2-

High

proliferation

ER-/HER2-

HER2+
$361(98.1)$

$352(95.7)$

$140(92.7)$

$108(98.2)$
4 (1.1)

$3(0.8)$

$12(3.3)$

$4(1.1)$

$9(6.0)$

$2(1.3)$

$0 \quad 2(1.8)$ 
Table 2: Clinicopathological associations of GLUD1 mRNA and GLUD1 protein expression in breast cancer

\section{GLUD1}

mRNA

\begin{tabular}{|c|c|c|c|c|c|c|}
\hline & $\begin{array}{c}\text { Low } \\
\text { n (\%) }\end{array}$ & $\begin{array}{l}\text { High } \\
\text { n (\%) }\end{array}$ & $\begin{array}{c}\chi^{2} \\
\text { (p-value) }\end{array}$ & $\begin{array}{c}\text { Low } \\
\text { n (\%) }\end{array}$ & $\begin{array}{c}\text { High } \\
\text { n (\%) }\end{array}$ & $\begin{array}{c}\chi^{2} \\
\text { (p-value) }\end{array}$ \\
\hline \multicolumn{7}{|c|}{ Tumour size (cm) } \\
\hline$<2.0$ & $344(55.3)$ & $278(44.7)$ & \multirow{2}{*}{$\begin{array}{c}0.52 \\
(0.473)\end{array}$} & $443(69.5)$ & $194(30.5)$ & \multirow{2}{*}{$\begin{array}{c}3.85 \\
(0.050)\end{array}$} \\
\hline$\geq 2.0$ & $713(53.6)$ & $618(46.4)$ & & $503(74.4)$ & $173(25.6)$ & \\
\hline
\end{tabular}

Grade

$\begin{array}{lllcccc}1 & 59(34.7) & 111(65.3) & 114.3 & 140(67.6) & 67(32.4) & 6.107 \\ 2 & 340(44.2) & 430(55.8) & (\mathbf{1 . 4 9 \times 1 0}-\mathbf{2 5}) & 300(39.8) & 130(30.2) & \mathbf{( 0 . 0 4 7 )} \\ 3 & 632(66.4) & 320(33.6) & & 505(75.0) & 168(25.0) & \end{array}$

\section{Histological type}

\begin{tabular}{|c|c|c|c|c|c|c|}
\hline $\begin{array}{l}\text { Ductal } \\
\text { (including } \\
\text { mixed) }\end{array}$ & $910(55.7)$ & $724(44.3)$ & $\begin{array}{c}42.9 \\
\left(2.7 \times 10^{-9}\right)\end{array}$ & $806(72.3)$ & $309(27.7)$ & $\begin{array}{c}5.74 \\
(0.220)\end{array}$ \\
\hline Lobular & $60(40.80$ & $87(59.2)$ & & $76(69.1)$ & $34(30.9)$ & \\
\hline $\begin{array}{l}\text { Medullary- } \\
\text { like }\end{array}$ & $27(84.4)$ & $5(15.6)$ & & $27(87.1)$ & $4(12.9)$ & \\
\hline Special type & $38(33.6)$ & $75(66.4)$ & & $37(64.91)$ & $20(35.1)$ & \\
\hline \multicolumn{7}{|c|}{ Lymph Node Stage } \\
\hline 1 & $515(49.8)$ & $520(50.2)$ & \multirow[t]{3}{*}{$18.5(\mathbf{0 . 0 0 0 1})$} & $585(73.8)$ & $208(26.2)$ & \multirow{3}{*}{$\begin{array}{c}4.53 \\
(0.104)\end{array}$} \\
\hline 2 & $354(56.9)$ & $268(43.1)$ & & $282(68.3)$ & $131(31.7)$ & \\
\hline 3 & $197(62.3)$ & $119(37.7)$ & & $78(64.9)$ & $26(25.0)$ & \\
\hline \multicolumn{7}{|c|}{ Estrogen Receptor } \\
\hline $\begin{array}{l}\text { Negative } \\
\text { Positive }\end{array}$ & $\begin{array}{l}385(81.2) \\
686(45.6)\end{array}$ & $\begin{array}{c}89(18.8) \\
820(54.4)\end{array}$ & $\begin{array}{c}184.7 \\
\left(\mathbf{4 . 5} \times 10^{-42}\right)\end{array}$ & $\begin{array}{l}275(82.3) \\
662(68.5)\end{array}$ & $\begin{array}{c}59(17.7) \\
304(31.5)\end{array}$ & $\begin{array}{c}23.50 \\
(\mathbf{0 . 0 0 0 0 0 1})\end{array}$ \\
\hline \multicolumn{7}{|c|}{ Progesterone Receptor } \\
\hline $\begin{array}{l}\text { Negative } \\
\text { Positive }\end{array}$ & $\begin{array}{l}611(65.0) \\
460(44.2)\end{array}$ & $\begin{array}{l}329(35.0) \\
580(55.8)\end{array}$ & $\begin{array}{c}85.8 \\
\left(1.6 \times 10^{-32}\right)\end{array}$ & $\begin{array}{l}390(76.0) \\
518(69.4)\end{array}$ & $\begin{array}{l}123(24.0) \\
228(30.6)\end{array}$ & $\begin{array}{c}6.56 \\
(\mathbf{0 . 0 1 0})\end{array}$ \\
\hline
\end{tabular}




\section{HER2}

$\begin{array}{lcccccc}\text { Negative } & 892(51.5) & 841(48.5) & 38.4 & 776(71.0) & 313(29.0) & 3.07 \\ \text { Positive } & 179(72.5) & 68(27.5) & (\mathbf{5 . 8 \times 1 0}-\mathbf{1 0}) & 128(77.6) & 37(22.4) & (0.080)\end{array}$

\section{Triple Negative}

$\begin{array}{lcccccc}\text { No } & 801(48.3) & 859(51.7) & 141.0 & 724(69.2) & 322(30.8) & \begin{array}{c}26.47 \\ (\mathbf{2 . 7} \times 10\end{array} \\ \text { Yes } & 270(54.1) & 50(15.6) & \left(\mathbf{1 . 6 x 1 0}^{-32}\right) & 197(86.0) & 32(14.0) & \left(\mathbf{r . 7}^{-3}\right)\end{array}$

SCMGENE/

IHC

molecular

subtypes

ER+/HER2-

High

$179(48.6) \quad 189(51.4)$

Proliferation

ER+/HER2-

Low

$153(41.6) \quad 215(58.4)$

Proliferation

Triple

Negative

$130(86.1) \quad 21(13.9)$

HER 2+

$81(73.6) \quad 29(26.4)$

106.9

$(\mathbf{5 . 1 \times 1 0}-\mathbf{2 3}) \quad 198(68.8) \quad 90(31.3)$ 
Table 3: Expression of GLUD1 in breast cancer and the expression of other molecular biomarkers

\section{GLUD1}

Low, $n(\%) \quad$ High, $n(\%) \quad \begin{gathered}\chi^{2} \\ (p-v a l u e)\end{gathered}$

c-MYC

Negative

$415(48.7)$

437 (51.3)

19.077

Positive

$111(67.3)$

54 (32.7)

$(<\mathbf{0 . 0 0 1})$

BCL2

Negative

211 (55.8)

167 (44.2)

5.235

Positive

376 (48.6)

397 (51.4)

(0.022)

Cyclin E

Negative

$169(45.6)$

$202(54.4)$

7.695

Positive

54 (62.1)

33 (37.9)

(0.006)

Ki67

Negative

$173(50.9)$

$167(49.1)$

0.521

Positive

403 (53.2)

354 (46.8)

(0.47)

pAKTs437

Negative

135 (61.6)

84 (38.4)

15.381

Positive

$290(46.3)$

337 (53.7)

$(<0.001)$

PI3K

Negative

346 (47.3)

385 (52.7)

12.555

Positive

$484(50.5)$

$474(49.5)$

$(<\mathbf{0 . 0 0 1})$ 
Table 4: Correlation of GLUD1 mRNA expression with other glutamine-related genes

\begin{tabular}{|c|c|c|c|c|c|}
\hline & \multicolumn{5}{|c|}{ GLUD1 mRNA } \\
\hline & $\begin{array}{r}\text { All cases } \\
(n=1,980)\end{array}$ & $\underset{(\mathrm{n}=368)}{\text { Luminal A }}$ & $\underset{(n=367)}{\text { Luminal B }}$ & $\begin{array}{c}\text { HER2+ } \\
(\mathrm{n}=110)\end{array}$ & $\begin{array}{c}\text { Basal } \\
(n=150)\end{array}$ \\
\hline & \multicolumn{5}{|c|}{ Correlation Coefficient (p-value) } \\
\hline MYC & $-0.204\left(3.9 \times 10^{-20}\right)$ & $-0.127(0.001)$ & $-0.110(0.015)$ & $-0.111(0.085)$ & $0.015(0.785)$ \\
\hline$N D R G 2$ & $-0.072(0.001)$ & $-0.007(0.850)$ & $0.002(0.970)$ & $-0.060(0.352)$ & $-0.040(0.475)$ \\
\hline$G L S$ & $0.039(0.087)$ & $0.151(0.000049)$ & $0.173(0.000122)$ & $0.029(0.656)$ & $0.117(0.033)$ \\
\hline$A L D H 4 A 1$ & $0.159\left(1.1 \times 10^{-12}\right)$ & $0.078(0.037)$ & $-0.040(0.377)$ & $0.120(0.063)$ & $0.232(0.000022)$ \\
\hline PRODH & $0.046(0.463)$ & $0.131(0.163)$ & $0.041(0.727)$ & $0.212(0.383)$ & $0.040(0.858)$ \\
\hline PYCR1 & $-0.070(0.002)$ & $-0.002(0.954)$ & $-0.020(0.662)$ & $0.051(0.432)$ & $-0.123(0.026)$ \\
\hline $\begin{array}{l}\text { ALDH18A } \\
1\end{array}$ & $0.110\left(9.8 \times 10^{-7}\right)$ & $0.201\left(5.6 \times 10^{-8}\right)$ & $0.158(0.000458)$ & $0.278(0.000013)$ & $0.091(0.100)$ \\
\hline$G L U L$ & $0.272(0.000011)$ & $0.166(0.077)$ & $0.402(0.000385)$ & $-0.256(0.290)$ & $0.081(0.713)$ \\
\hline$S L C 1 A 5$ & $0.130\left(9.8 \times 10^{-7}\right)$ & $0.255\left(3.6 \times 10^{-12}\right)$ & $0.192(0.000019)$ & $0.202(0.002)$ & $0.128(0.020)$ \\
\hline$S L C 38 A 1$ & $0.334\left(1.4 \times 10^{-17}\right)$ & $0.297\left(4.8 \times 10^{-16}\right)$ & $0.183(0.000048)$ & $0.313\left(7.7 \times 10^{-7}\right)$ & $0.108(0.049)$ \\
\hline SLC38A2 & $0.154\left(6.1 \times 10^{-12}\right)$ & $0.207\left(2.1 \times 10^{-8}\right)$ & $0.154(0.001)$ & $0.082(0.207)$ & $0.188(0.001)$ \\
\hline SLC38A3 & $-0.029(0.200)$ & $0.048(0.186)$ & $0.154(0.001)$ & $0.077(0.235)$ & $-0.117(0.034)$ \\
\hline SLC38A5 & $-0.125\left(2.3 \times 10^{-8}\right)$ & $-0.073(0.050)$ & $-0.161(0.000349)$ & $-0.073(0.261)$ & $-0.683(0.135)$ \\
\hline$S L C 38 A 7$ & $-0.025(0.283)$ & $0.072(0.053)$ & $0.072(0.114)$ & $0.053(0.415)$ & $0.059(0.283)$ \\
\hline SLC38A8 & $-0.047(0.035)$ & $-0.041(0.275)$ & $-0.046(0.314)$ & $-0.119(0.066)$ & $-0.066(0.232)$ \\
\hline SLC7A11 & $-0.027(0.230)$ & $-0.013(0.721)$ & $0.074(0.100)$ & $0.017(0.798)$ & $-0.044(0.421)$ \\
\hline SLC7A5 & $-0.380\left(4.4 \times 10^{-69}\right)$ & $-0.161(0.000014)$ & $-0.237\left(1.1 \times 10^{-7}\right)$ & $-0.148(0.022)$ & $-0.112(0.042)$ \\
\hline SLC7A6 & $-0.205\left(3.7 \times 10^{-20}\right)$ & $-0.127(0.001)$ & $-0.152(0.001)$ & $-0.52(0.421)$ & $0.162(0.003)$ \\
\hline SLC7A7 & $-0.363\left(1.4 \times 10^{-62}\right)$ & $-0.361\left(1.4 \times 10^{-23}\right)$ & $-0.316\left(8.1 \times 10^{-13}\right)$ & $-0.214(0.001)$ & $0.009(0.867)$ \\
\hline SLC7A8 & $0.409\left(1.4 \times 10^{-17}\right)$ & $0.275\left(6.0 \times 10^{-14}\right)$ & $0.171(0.000144)$ & $0.245(0.000130)$ & $0.128(0.020)$ \\
\hline SLC6A19 & $-0.009(0.700)$ & $-0.041(0.273)$ & $0.036(0.503)$ & $0.030(0.643)$ & $-0.107(0.053)$ \\
\hline MTOR & $0.053(0.018)$ & $0.135(0.000293)$ & $-0.017(0.701)$ & $0.053(0.413)$ & $0.200(0.000264)$ \\
\hline$P I K 3 A P 1$ & $-0.200\left(2.1 \times 10^{-19}\right)$ & $-0.060(0.106)$ & $-0.131(0.004)$ & $-0.157(0.015)$ & $0.027(0.631)$ \\
\hline$V E G F A$ & $-0.118\left(1.4 \times 10^{-7}\right)$ & $0.097(0.010)$ & $0.003(0.952)$ & $-0.083(0.202)$ & $-0.283\left(1.7 \times 10^{-7}\right)$ \\
\hline$V E G F B$ & $-0.080(0.000390)$ & $-0.199\left(7.3 \times 10^{-8}\right)$ & $-0.167(0.000204)$ & $-0.068(0.293)$ & $-0.090(0.103)$ \\
\hline$A K T 1$ & $0.089(0.000075)$ & $0.033(0.376)$ & $0.027(0.555)$ & $0.064(0.327)$ & $-0.046(0.403)$ \\
\hline
\end{tabular}




\begin{tabular}{lccccc}
$A T F 4$ & $\mathbf{- 0 . 0 7 0 ( \mathbf { 0 . 0 0 2 } )}$ & $0.004(0.915)$ & $0.060(0.184)$ & $0.022(0.737)$ & $-0.068(0.217)$ \\
$B R C A 1$ & $\mathbf{0 . 0 8 6 ( \mathbf { 0 . 0 0 0 1 2 1 } )}$ & $\mathbf{0 . 1 0 2 ( \mathbf { 0 . 0 0 6 } )}$ & $\mathbf{0 . 1 0 9}(\mathbf{0 . 0 1 6})$ & $0.092(0.137)$ & $0.069(0.213)$ \\
\hline
\end{tabular}

Table 5: Correlation of GLUD1 protein expression with other glutamine-related proteins

\section{GLUD1}

\begin{tabular}{lccc} 
& Low, n (\%) & High, n (\%) & $\begin{array}{c}\chi^{2} \\
\text { (p-value) }\end{array}$ \\
\hline PRODH & & & \\
Negative & $546(74.5)$ & $187(25.5)$ & \\
Positive & $138(71.1)$ & $56(28.9)$ & $0.892(0.345)$
\end{tabular}

ALDH18A1

$\begin{array}{llll}\text { Negative } & 370(76.6) & 113(23.4) & \\ \text { Positive } & 307(68.7) & 140(31.1) & 7.362(\mathbf{0 . 0 0 7})\end{array}$

ALDH4A1

$\begin{array}{llll}\text { Negative } & 337(74.9) & 113(25.1) & 0.597(0.440) \\ \text { Positive } & 329(72.6) & 124(27.4) & \\ \text { PYCR1 } & & & \\ \text { Negative } & 195(69.9) & 84(30.1) & 1.234(0.267) \\ \text { Positive } & 352(73.6) & 126(26.4) & \\ \text { GLS } & & & \\ \text { Negative } & 634(72.2) & 244(27.8) & 0.304(0.581) \\ \text { Positive } & 91(74.6) & 31(25.4) & \end{array}$

SLC7A11

$\begin{array}{llll}\text { Negative } & 411(73.7) & 147(26.3) & \\ \text { Positive } & 122(77.7) & 35(22.3) & \end{array}$

\section{SLC7A5}

$\begin{array}{llll}\text { Negative } & 581(71.9) & 227(28.1) & 5.053(\mathbf{0 . 0 2 5}) \\ \text { Positive } & 148(80.0) & 37(20.0)\end{array}$

\section{SLC3A2}




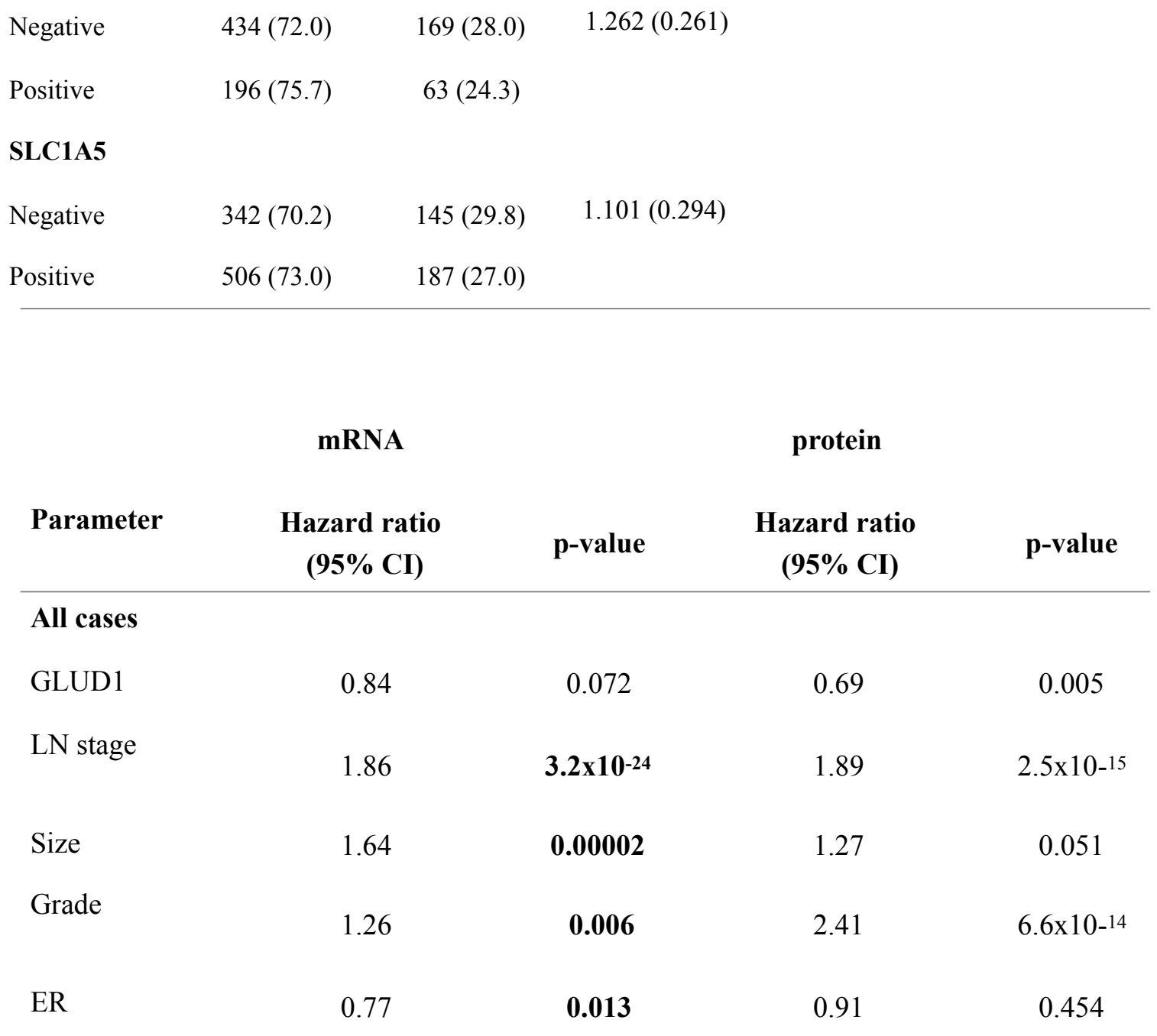

Table 6: GLUD1 and patient outcome 
Supplementary Table 1: Clinicopathological parameters of the METABRIC and Nottingham primary breast cancer series

\begin{tabular}{|c|c|c|}
\hline & $\begin{array}{c}\text { METABRIC series } \\
\text { n (\%) }\end{array}$ & $\begin{array}{c}\text { Nottingham TMA } \\
\text { series } \\
\text { n (\%) }\end{array}$ \\
\hline \multicolumn{3}{|l|}{ Menopausal status } \\
\hline Pre & $435(22.0)$ & $524(40.3)$ \\
\hline Post & $1534(77.4)$ & $776(59.7)$ \\
\hline \multicolumn{3}{|l|}{ Age } \\
\hline$>50$ years & $1426(78.6)$ & $830(63.2)$ \\
\hline$\leq 50$ years & $424(21.4)$ & $483(36.8)$ \\
\hline \multicolumn{3}{|l|}{ Tumour size } \\
\hline$\leq 2 \mathrm{~cm}$ & $1337(68.2)$ & $637(48.5)$ \\
\hline$>2 \mathrm{~cm}$ & $623(31.8)$ & $676(51.5)$ \\
\hline \multicolumn{3}{|l|}{ Grade } \\
\hline 1 & $169(8.9)$ & $207(15.8)$ \\
\hline 2 & $770(40.7)$ & $430(32.8)$ \\
\hline 3 & $952(50.3)$ & $673(51.4)$ \\
\hline \multicolumn{3}{|l|}{ Tumour type } \\
\hline Ductal (including mixed) & $1545(83.5)$ & $1105(84.2)$ \\
\hline Lobular & $148(8.0)$ & $110(8.4)$ \\
\hline Medullary-like & $32(1.7)$ & $31(2.4)$ \\
\hline Miscellaneous & $12(0.6)$ & $10(0.8)$ \\
\hline Special type & $113(6.1)$ & $57(4.3)$ \\
\hline \multicolumn{3}{|l|}{ Lymph Node Stage } \\
\hline 1 & $1035(52.5)$ & $793(60.5)$ \\
\hline 2 & $623(31.4)$ & $413(31.5)$ \\
\hline 3 & $315(16.0)$ & $104(7.9)$ \\
\hline \multicolumn{3}{|l|}{ Follow-up Status } \\
\hline Alive & $1070(55.7)$ & $683(52.0)$ \\
\hline Died from Breast Cancer & $505(26.3)$ & $434(33.1)$ \\
\hline Died from other causes & $345(18.0)$ & $196(14.9)$ \\
\hline
\end{tabular}


ER

$\begin{array}{lcc}\text { Negative } & 472(23.8) & 334(25.7) \\ \text { Positive } & 1508(76.2) & 966(74.3) \\ \text { PgR } & 938(47.4) & 513(40.7) \\ \text { Negative } & 1042(52.6) & 746(59.3) \\ \text { Positive } & & \\ \text { HER2 } & 1734(87.5) & 1079(86.7) \\ \text { Negative } & 246(12.5) & 165(13.3) \\ \text { Positive } & \end{array}$


Supplementary Table 2: Correlation of GLUD1 mRNA expression in molecular subtypes with other genes using Breast Cancer Gene-Expression Miner

\begin{tabular}{lcccc}
\hline & $\begin{array}{c}\text { All cases } \\
(\mathrm{n}=5,262)\end{array}$ & $\begin{array}{c}\text { Luminal } \\
(\mathrm{n}=3,765)\end{array}$ & $\begin{array}{c}\text { HER2+ } \\
(\mathrm{n}=124)\end{array}$ & $\begin{array}{c}\text { Triple negative } \\
(\mathrm{n}=374)\end{array}$ \\
\hline MYC & $0.02(0.149)$ & $0.10(<\mathbf{0 . 0 0 0 1})$ & $-0.01(0.955)$ & $-0.07(0.1669)$ \\
GLS & & & & \\
ALDH4A1 & $-0.12(<\mathbf{0 . 0 0 0 1})$ & $-0.08(<\mathbf{0 . 0 0 0 1})$ & $-0.04(0.699)$ & $-0.08(0.1139)$ \\
$P R O D H$ & $0.17(<\mathbf{0 . 0 0 0 1})$ & $0.10(<\mathbf{0 . 0 0 0 1})$ & $0.25(0.0045)$ & $0.31(<0.0001)$ \\
$P Y C R 1$ & $-0.05(0.0002)$ & $0.09(\mathbf{0 . 0 0 1 4})$ & $-0.10(0.5714)$ & $0.32(\mathbf{0 . 0 0 3})$ \\
ALDH18A1 & $0.21(<\mathbf{0 . 0 0 0 1})$ & $-0.03(0.055)$ & $0.02(0.803)$ & $0.25(<\mathbf{0 . 0 0 0 1})$ \\
GLUL & $0.16(<\mathbf{0 . 0 0 0 1})$ & $0.19(<\mathbf{0 . 0 0 0 1})$ & $0.33(0.0003)$ & $0.15(\mathbf{0 . 0 0 4 4})$ \\
& $0.26(<\mathbf{0 . 0 0 0 1})$ & $0.20(<\mathbf{0 . 0 0 0 1})$ & $0.07(0.421)$ & $0.30(<0.0001)$
\end{tabular}



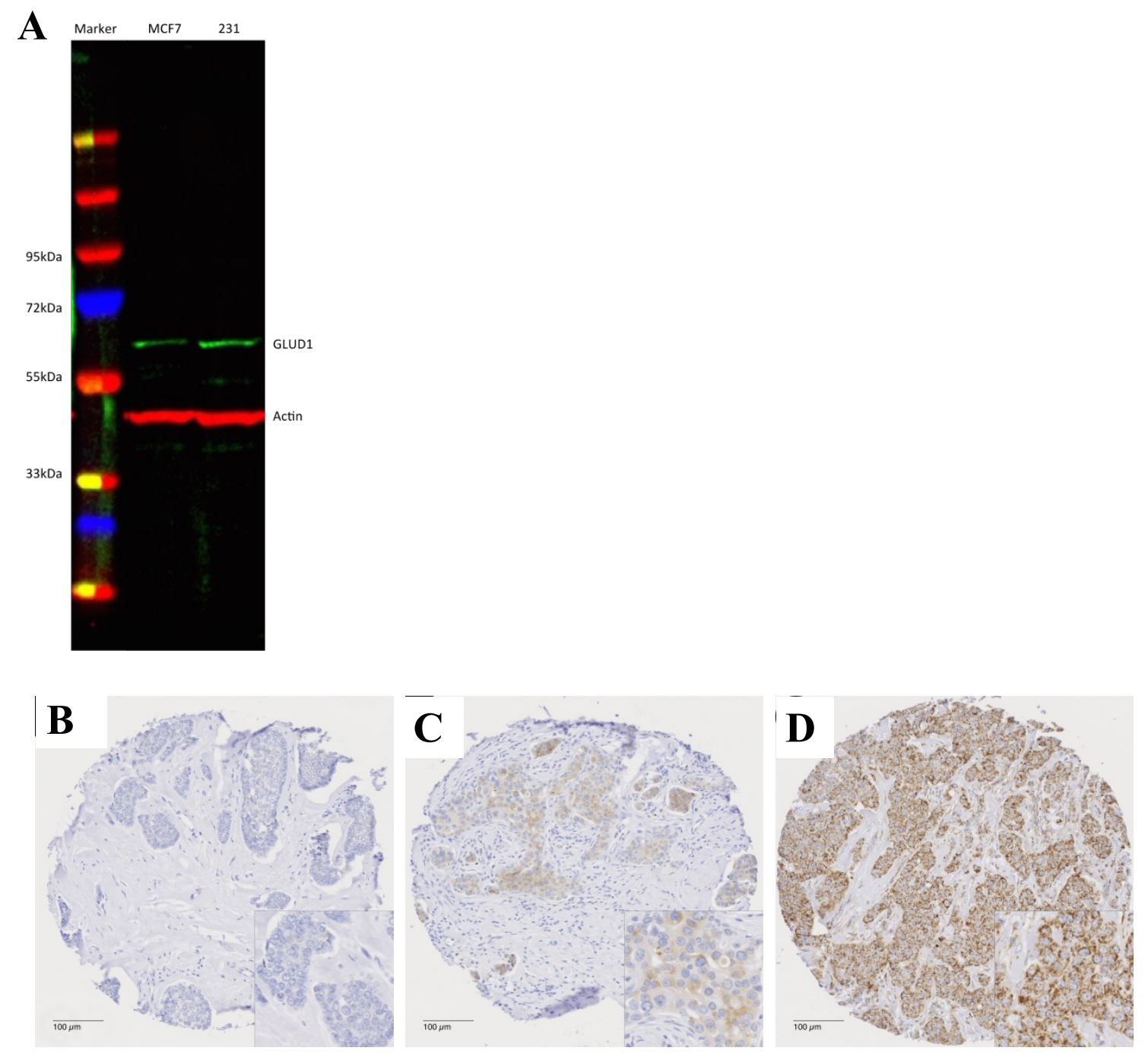

Figure 1: GLUD1 Protein Expression in Breast Cancer.

A) Antibody validation of GLUD1 shows a single specific band is observed at the correct molecular weight of 62kDa. Representative photomicrographs depicting: B) negative GLUD1 expression, C) low GLUD1 expression and D) high GLUD1 expression in BC TMA using IHC. 

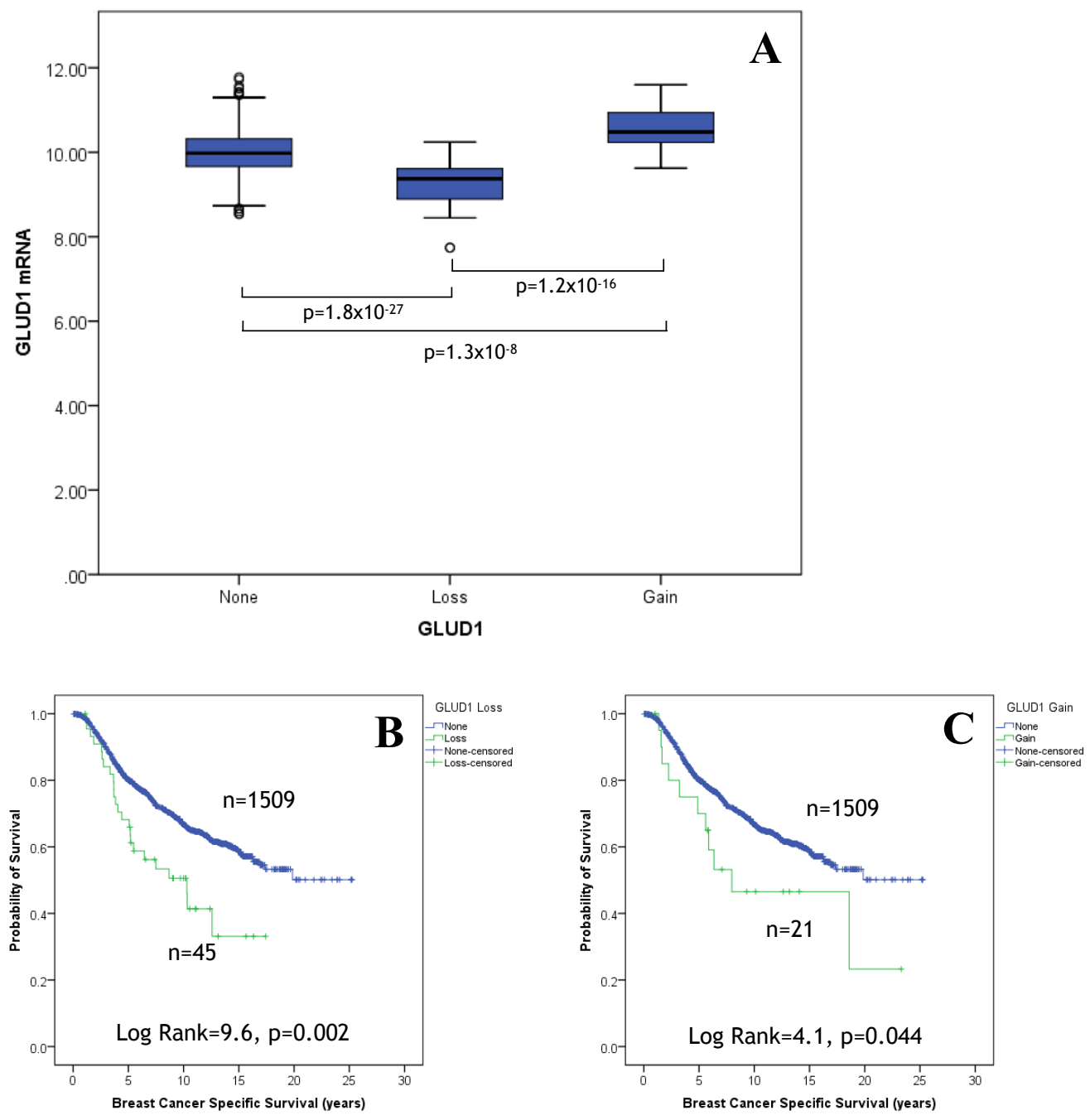

Figure 2. GLUD1 Copy Number Aberrations and relationship with A) mRNA expression B) loss vs BCSS, C) amplification vs BCSS 

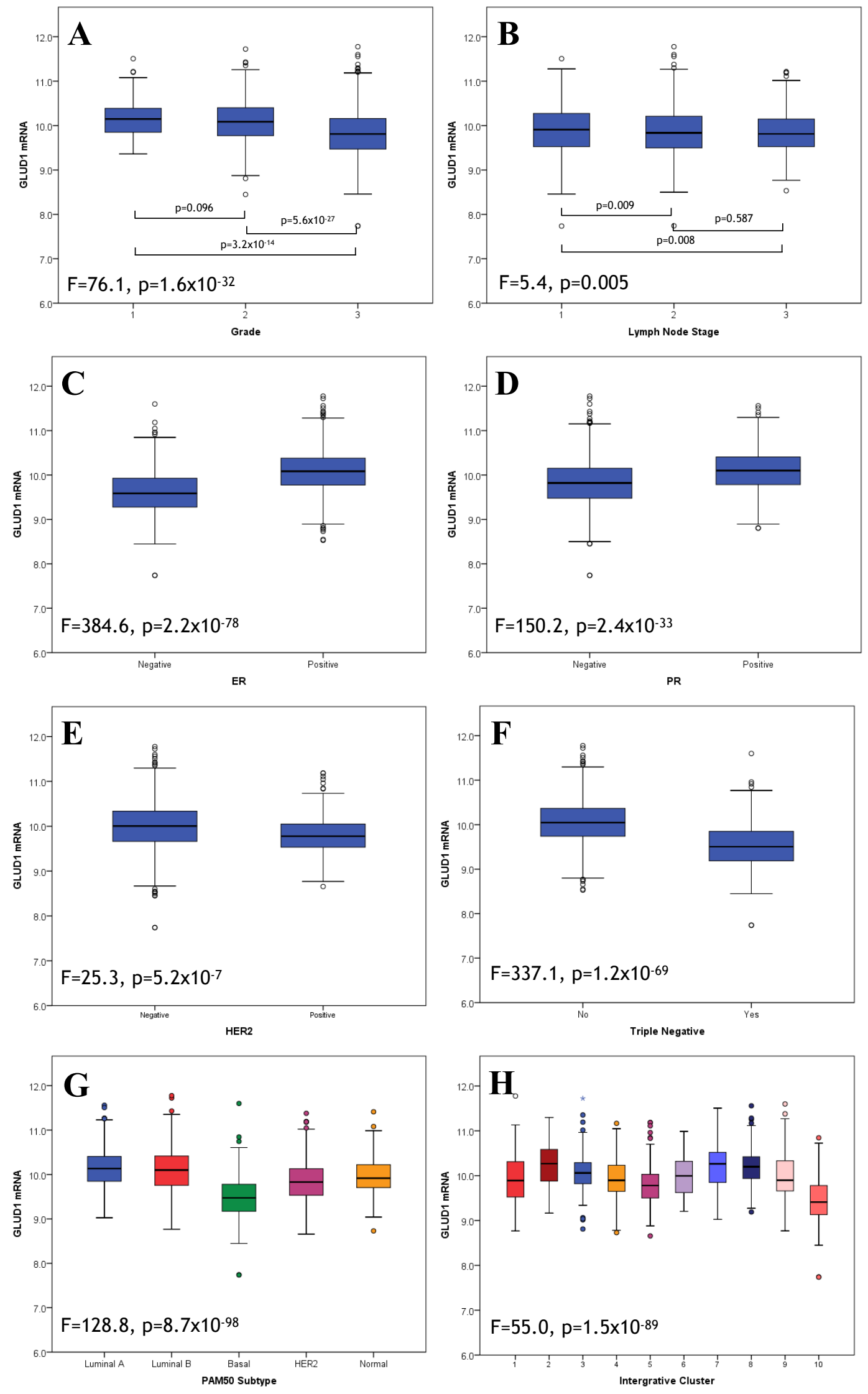

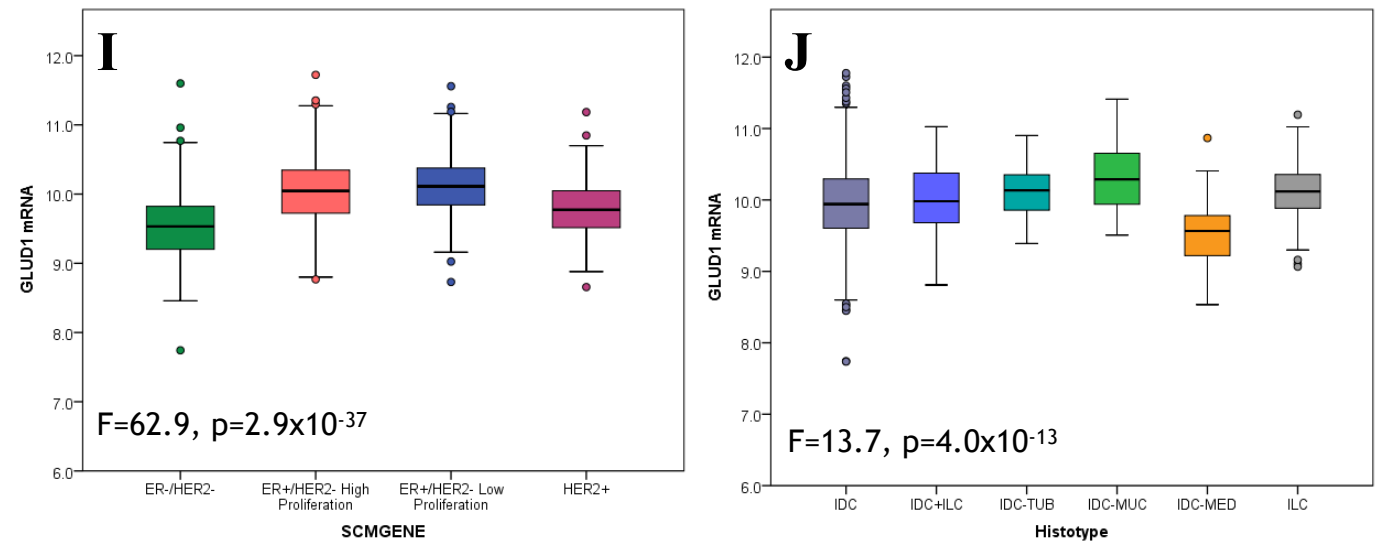

Figure 3: GLUD1 expression and its association with clinicopathological parameters and molecular subtypes: GLUD1 and A) tumour grade, B) lymph node stage, C) ER status, D), PR status, E) HER2 status, F) Triple Negative status, G) PAM50 subtypes, H) METABRIC Integrative Clusters, I) SMCGENE subtypes, J) Histological Type (IDC=Invasive ductal carcinoma, IDC+ILC=Invasive ductal carcinoma and invasive lobular carcinoma, IDCTUB=Tubular, IDC-MUC=Mucinous, IDC-MED=Medullary, ILC=Invasive lobular carincoma) 

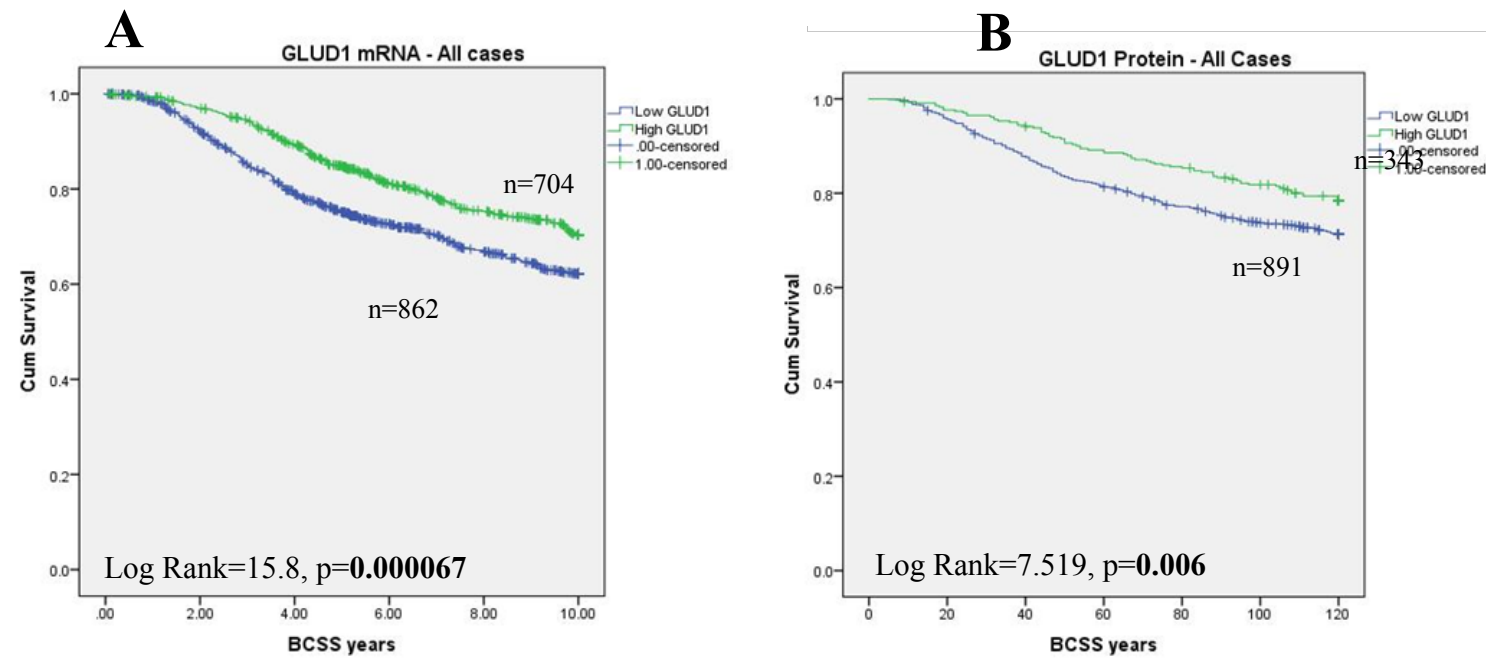

Figure 4. GLUD1 and Breast Cancer Specific Survival (BCSS) at 10 years: A) GLUD1 vs BCSS in all cases, B) GLUD1 vs BCSS in all cases. 

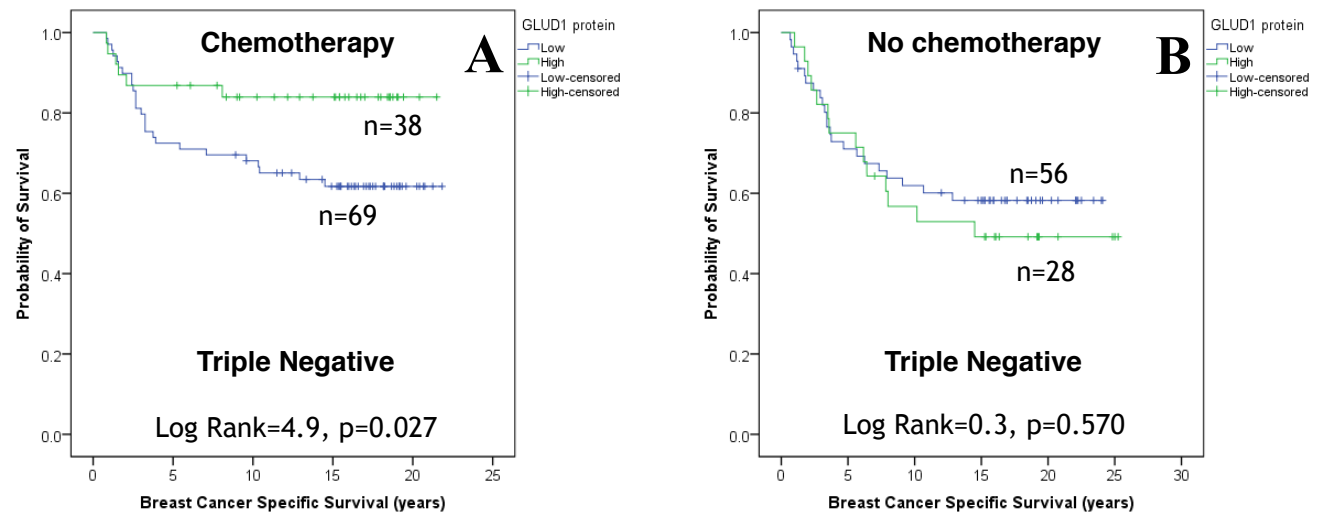

Figure 5. GLUD1 protein expression and breast cancer patient outcome in Triple Negative tumours according to adjuvant treatment: A) protein in patients treated with chemotherapy, B) protein in patients not treated with chemotherapy. Green=high protein expression; blue $=$ low protein expression. 

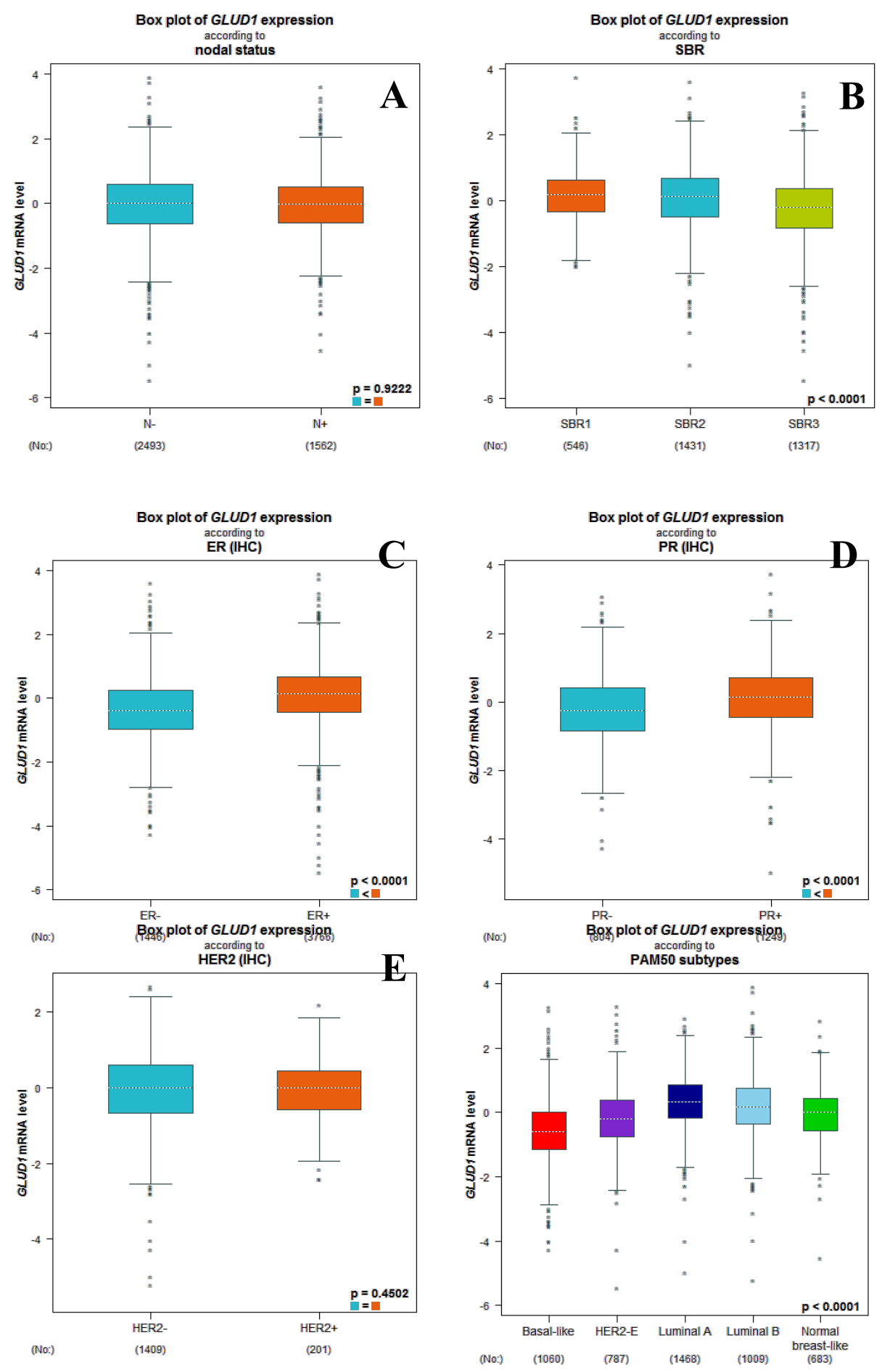

Sup- ple-

mentary Figure 1:

GLUD1 gene expression and its association, using Breast Cancer Gene-Expression Miner v4.0, with: A) lymph node stage, B) tumour grade, C) ER status, D) PR status, E) HER2 status, F) PAM50 subtypes. 

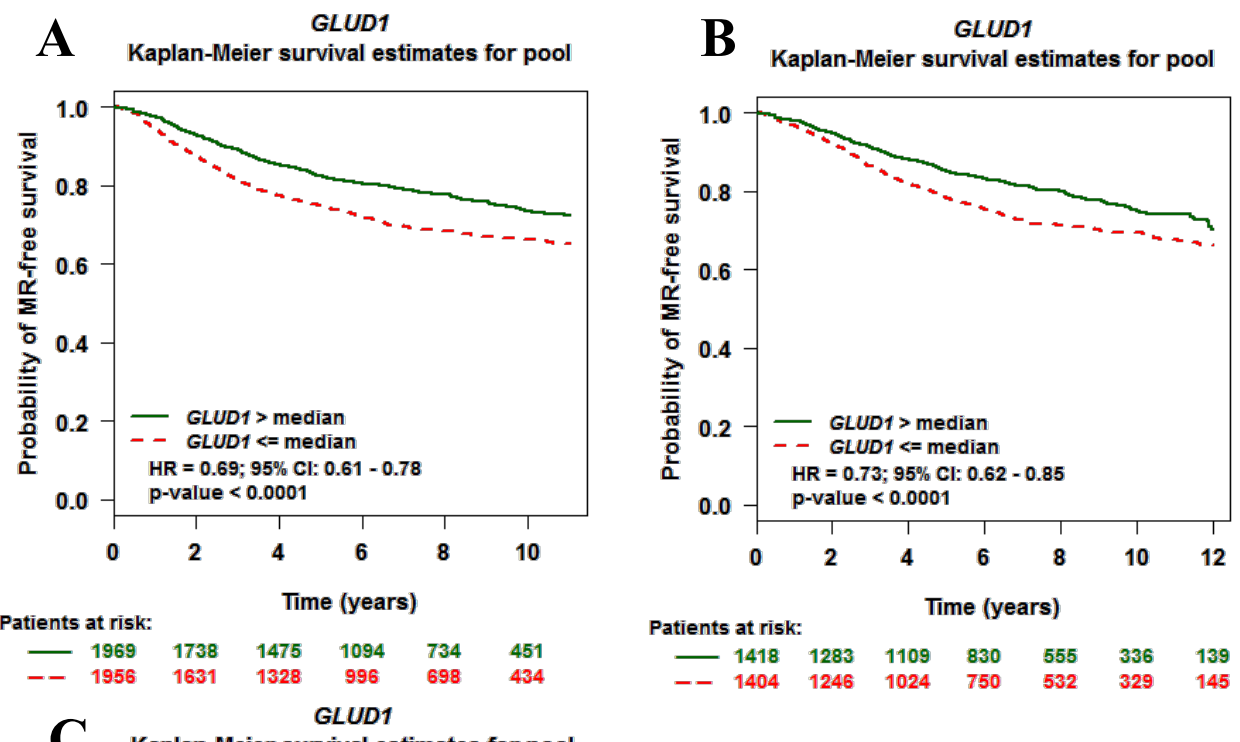

C Kaplan-Meier survival estimates for pool

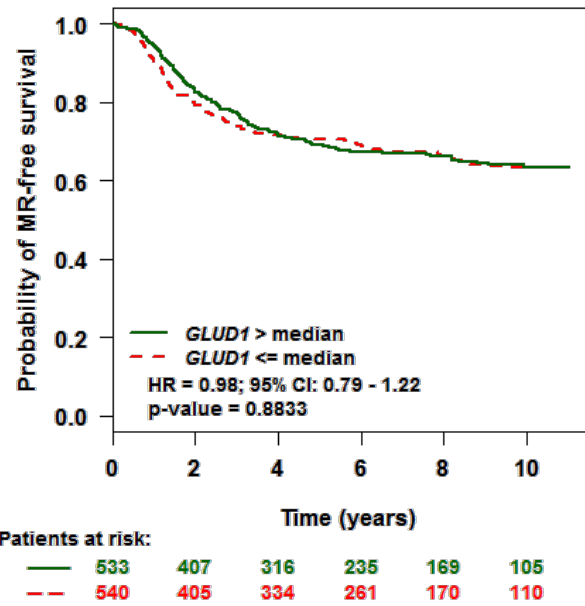

Supplementary Figure 2. GLUD1 mRNA and breast cancer patient outcome using Breast Cancer Gene-Expression Miner: A) Unselected cases, B) ER+ disease, C) ER- disease. 


\section{References}

1. Hanahan, D. and R.A. Weinberg, Hallmarks of cancer: the next generation. Cell, 2011. 144(5): p. 646-74.

2. Warburg, O., On the origin of cancer cells. Science, 1956. 123(3191): p. 309-14.

3. Alberghina, L. and D. Gaglio, Redox control of glutamine utilization in cancer. Cell Death Dis, 2014. 5: p. e1561.

4. Yang, L., et al., Metabolic shifts toward glutamine regulate tumor growth, invasion and bioenergetics in ovarian cancer. Mol Syst Biol, 2014. 10: p. 728.

5. Green, A.R., et al., MYC functions are specific in biological subtypes of breast cancer and confers resistance to endocrine therapy in luminal tumours. Br J Cancer, 2016. 114(8): p. 917-28.

6. $\mathrm{Hu}, \mathrm{W}$., et al., Glutaminase 2, a novel p53 target gene regulating energy metabolism and antioxidant function. Proc Natl Acad Sci U S A, 2010. 107(16): p. 7455-60.

7. $\quad$ Polyak, K., et al., A model for p53-induced apoptosis. Nature, 1997. 389(6648): p. 300-5.

8. Cao, M.D., et al., Metabolic characterization of triple negative breast cancer. BMC Cancer, 2014. 14: p. 941.

9. Gross, M.I., et al., Antitumor activity of the glutaminase inhibitor CB-839 in triplenegative breast cancer. Mol Cancer Ther, 2014. 13(4): p. 890-901.

10. Kim, S., et al., Expression of glutamine metabolism-related proteins according to molecular subtype of breast cancer. Endocr Relat Cancer, 2013. 20(3): p. 339-48.

11. Kanaan, Y.M., et al., Metabolic profile of triple-negative breast cancer in AfricanAmerican women reveals potential biomarkers of aggressive disease. Cancer $\mathrm{Ge}-$ nomics Proteomics, 2014. 11(6): p. 279-94.

12. Craze, M.L., et al., MYC regulation of glutamine-proline regulatory axis is key in luminal B breast cancer. Br J Cancer, 2018. 118(2): p. 258-265.

13. Plaitakis, A., et al., The Glutamate Dehydrogenase Pathway and Its Roles in Cell and Tissue Biology in Health and Disease. Biology (Basel), 2017. 6(1).

14. Duran, R.V., et al., Glutaminolysis activates Rag-mTORC1 signaling. Mol Cell, 2012. 47(3): p. 349-58.

15. Jin, L., et al., Glutamate dehydrogenase 1 signals through antioxidant glutathione peroxidase 1 to regulate redox homeostasis and tumor growth. Cancer Cell, 2015. 27(2): p. 257-70.

16. Curtis, C., et al., The genomic and transcriptomic architecture of 2,000 breast tumours reveals novel subgroups. Nature, 2012. 486(7403): p. 346-52.

17. Silwal-Pandit, L., et al., TP53 mutation spectrum in breast cancer is subtype specific and has distinct prognostic relevance. Clin Cancer Res, 2014. 20(13): p. 3569-80.

18. Camp, R.L., M. Dolled-Filhart, and D.L. Rimm, X-tile: a new bio-informatics tool for biomarker assessment and outcome-based cut-point optimization. Clin Cancer Res, 2004. 10(21): p. 7252-9.

19. Jezequel, P., et al., bc-GenExMiner: an easy-to-use online platform for gene prognostic analyses in breast cancer. Breast Cancer Res Treat, 2012. 131(3): p. 765-75.

20. Abd El-Rehim, D.M., et al., High-throughput protein expression analysis using tissue microarray technology of a large well-characterised series identifies biologically dis- 
tinct classes of breast cancer confirming recent cDNA expression analyses. Int J Cancer, 2005. 116(3): p. 340-50.

21. McCarty, K.S., Jr. and K.S. McCarty, Sr., Histochemical approaches to steroid receptor analyses. Semin Diagn Pathol, 1984. 1(4): p. 297-308.

22. McShane, L.M., et al., REporting recommendations for tumour MARKer prognostic studies (REMARK). Br J Cancer, 2005. 93(4): p. 387-91.

23. Jerby, L., et al., Metabolic associations of reduced proliferation and oxidative stress in advanced breast cancer. Cancer Res, 2012. 72(22): p. 5712-20.

24. Tyanova, S., et al., Proteomic maps of breast cancer subtypes. Nat Commun, 2016. 7: p. 10259.

25. El Ansari, R., et al., Altered glutamine metabolism in breast cancer; subtype dependencies and alternative adaptations. Histopathology, 2018. 72(2): p. 183-190.

26. Sancak, Y., et al., Ragulator-Rag complex targets mTORC1 to the lysosomal surface and is necessary for its activation by amino acids. Cell, 2010. 141(2): p. 290-303.

27. Sancak, Y., et al., The Rag GTPases bind raptor and mediate amino acid signaling to mTORC1. Science, 2008. 320(5882): p. 1496-501.

28. Nicklin, P., et al., Bidirectional transport of amino acids regulates $m T O R$ and autophagy. Cell, 2009. 136(3): p. 521-34.

29. Kim, S.G., G.R. Buel, and J. Blenis, Nutrient regulation of the mTOR complex 1 signaling pathway. Mol Cells, 2013. 35(6): p. 463-73. 